\title{
Optical stalagmite grey scale as a proxy of temperature from Central China
}

\author{
YUHUi LIU* AND ZHILING LI \\ Faculty of Materials Science and Chemistry, China \\ University of Geosciences, Wuhan 430078, China \\ (*correspondence: yhliu@cug.edu.cn)
}

With precise chronology and geochemical indicators, stalagmites could reveal climate changes on both short[1] and long time scales[2] and provide direct evidence for investigating climate driving mechanism. Some stalagmites with clear laminations could provide the precise details of the duration of abrupt climate events[3]. In addition to geochemical indicators, optical grey scale levels have been reported to be another useful proxy, which could reveal details of both local rainfall or temperature change[4-5]. Because of uncertainties this approach has not become as popluarl as other proxies.

A growing stalagmite, named as HS19-04, with clear annual growth bandings, collected in 2019 from Heshang Cave, located in the middle reaches of Yangtze River $\left(30.44^{\circ} \mathrm{N}\right.$, $110.42^{\circ} \mathrm{E}$ ), Central China, shows that the optical grey scale information has the potenial to be an efficient climate indicator. Based on U-Th dating conbined with layer counting, the chronlogy of HS19-04 has been precisely constructed, indicating this stalagmite was growing from $1650 \mathrm{AD}$, with an average growth rate over $400 \mu \mathrm{m} / \mathrm{yr}$. Using the image processing software 'Image-J', the layered structure of HS19-04 has been recorded and transformed into a scale of grey values (256 grey values, $0=$ black; $256=$ white). The comparison between the grey scale data and the instrumental annual mean temperature in Yichang shows that the dark layers of HS19-04 correspond to high temperatures. Based on the response, the local temperature variation from $1650 \mathrm{AD}$ has been reconstructed by the grey scale sequence of stalagmite HS19-04.

[1] Zhang et al. (2018) Sci. Rep. 8, 12344. [2] Chen et al. (2016) Science 534: 640-646. [3] Liu et al. (2013) Nature Geosci. 6: 117-120. [4] Muangsong et al. (2011) Science Asia, 37262(37):262-267. [5] Niggemann et al. (2003) Quaternary Sci. Rev. 22: 555-567. 